\title{
Posterior ankle arthroscopy: current state of the art
}

\author{
C Niek Van Dijk, ${ }^{1,2,3}$ Gwendolyn Vuurberg, ${ }^{1}$ Jorge Batista, ${ }^{4}$ Pieter d'Hooghe ${ }^{5}$
}

Handling editor Leendert Blankevoort

${ }^{1}$ Department of Orthopaedic Surgery, Academic Medical Center, Amsterdam, The Netherlands

${ }^{2}$ FIFA Medical Center of Excellence, Clinica Saude Atlantica, Porto, Portugal ${ }^{3}$ FIFA Medical Center of Excellence, Ripoll y de Prado \& van Dijk Sport Clinic, Madrid, Spain

${ }^{4}$ Centro Artroscópico Jorge Batista, Buenos Aires, Argentina ${ }^{5}$ Department of Orthopaedic Surgery, Aspetar Hospital, Doha, Qatar

\section{Correspondence to} Gwendolyn Vuurberg, Department of Orthopaedic Surgery, Academic Medical Center, POB 22700, Amsterdam 1100 DE, The Netherlands; $G$. Vuurberg@amc.uva.n

Received 11 April 2017 Revised 11 June 2017 Accepted 14 June 2017 Published Online First 7 August 2017
CrossMark

To cite: Van Dijk CN Vuurberg G, Batista J, et al. JISAKOS 2017:2:269-277.

\section{ABSTRACT}

The most common hindfoot pathologies seen in clinical practice and sports medicine are posterior ankle impingement and osteoarthrosis (OA). Both these-and other pathologies such as insertional tendinitis and Haglund's disease-may cause significant disability, in both everyday life and during sporting activities. Posttraumatic OA alone causes a healthcare burden of over 3 billion US dollars per year. An adequate approach of these pathologies is required to minimise this healthcare burden and additionally to maintain patients' economic productiveness. The aim of this article is to outline the most important evidence-based indications concerning posterior ankle arthroscopy focusing on diagnostics, surgical techniques, complications, geographical differences and future developments in the field of hindfoot arthroscopy. Initially, the treatment of hindfoot pathology is conservative. If adequate conservative treatment does not result in a good response, surgery may be indicated. Over the last three decades, arthroscopy of the ankle joint has become a standardised and important procedure, with numerous indications for both anterior and posterior pathology. Since 2000, a two-portal hindfoot arthroscopic approach has been described and used globally in clinical practice. Some of the indications that may be addressed using this approach are the treatment of posteriorly located osteochondral defects, posterior ankle impingement, pathology of the deep portion of the deltoid ligament, Cedell fracture, tarsal tunnel release, loose bodies and tibiotalar or subtalar arthrodesis. Tendon pathology can also be treated using posterior portals; however, this is beyond the scope of this review.

\section{INTRODUCTION}

Ankle disorders: prevalence and societal impact Ankle disorders may cause significant burden to both professional athletes and to the non-sports population. Posterior ankle impingement is especially common in both football players and ballet dancers-due to high loads in plantar flexion. ${ }^{1}$ Post-traumatic osteoarthritis is another common, and no less important, entity in orthopaedic practice. However, little data exist regarding its prevalence and relative disease. In 2006, it was reported that approximately 5.6 million individuals suffered from post-traumatic OA in the USA to such a degree that an orthopaedic surgeon was consulted for their symptoms. About $85.5 \%$ of the costs associated with arthritis are estimated to be attributable to posttraumatic OA. A database of 662 OA patients showed that $9.8 \%$ of all cases of knee OA were post-traumatic, while $1.6 \%$ of hip OA was post-traumatic and $79.5 \%$ of ankle OA was post-traumatic. ${ }^{2}$ Post-traumatic OA, causes an annual financial burden of more than US $\$ 3$ billion, or $0.15 \%$ of the total US healthcare costs. ${ }^{2}$

\section{History of ankle arthroscopy}

The field of arthroscopic foot and ankle surgery has progressed tremendously since its inception in $1939 .^{3}$ Access to the posterior compartment of the ankle and subtalar joint historically has been performed in combination with a two-portal anterior approach, with the patient in the supine position. A third posterolateral portal was used mainly for irrigation or for the introduction of a grasper in order to remove a loose body in the posterior compartment. A posteromedial portal was regarded as dangerous because of potential nerve damage and damage to the posterior tibial artery and posteromedial tendons. ${ }^{4}$ In 2000, van Dijk et $a l^{5}$ developed a two-portal technique for hindfoot arthroscopy with the patient in the prone position. This approach is currently used as the standard approach for posterior pathology (figure 1). This technique provides excellent access to the posterior ankle compartment, subtalar joint and also the extra-articular structures, thus allowing for the inspection and treatment of posterior ankle pathology such as posterior ankle impingement and flexor hallucis longus (FHL) tendinopathy. ${ }^{5-8}$ This approach can also be used to treat talar osteochondral defects (OCDs), removal of loose bodies or to perform arthroscopic ankle fusion, subtalar fusion or a combined ankle and subtalar fusion. Additional proceduress are tarsal tunnel release and peroneal groove deepening for recurrent peroneal tendon dislocation.

Ankle arthroscopy has expanded to become an important therapeutic technique in the management of disorders of the ankle joint. ${ }^{3910}$ As the indications for hindfoot arthroscopy have increased, so has its usage. It is the procedure of choice for the treatment of chronic and post-traumatic pathologies due to low morbidity rates, more rapid rehabilitation and favourable cosmetic results compared with conventional open surgical procedures. ${ }^{811}$

\section{Reviews and state-of-the-art or current concept articles}

Box 1 highlights six articles that the authors profess to be key in the development of posterior ankle arthroscopy. This article is the first state-of-the-art overview on ankle arthroscopy of the posterior ankle joint that discusses the diagnostics prior to arthroscopic treatment, the technique for posterior ankle arthroscopy, the complications, the pitfalls, any regional or geographical differences and future directions.

\section{CURRENT STATE OF THE ART Diagnostics}

Thorough history taking and physical examination are the key to ensure a working hypothesis. For each pathology, specific indications may be found, 

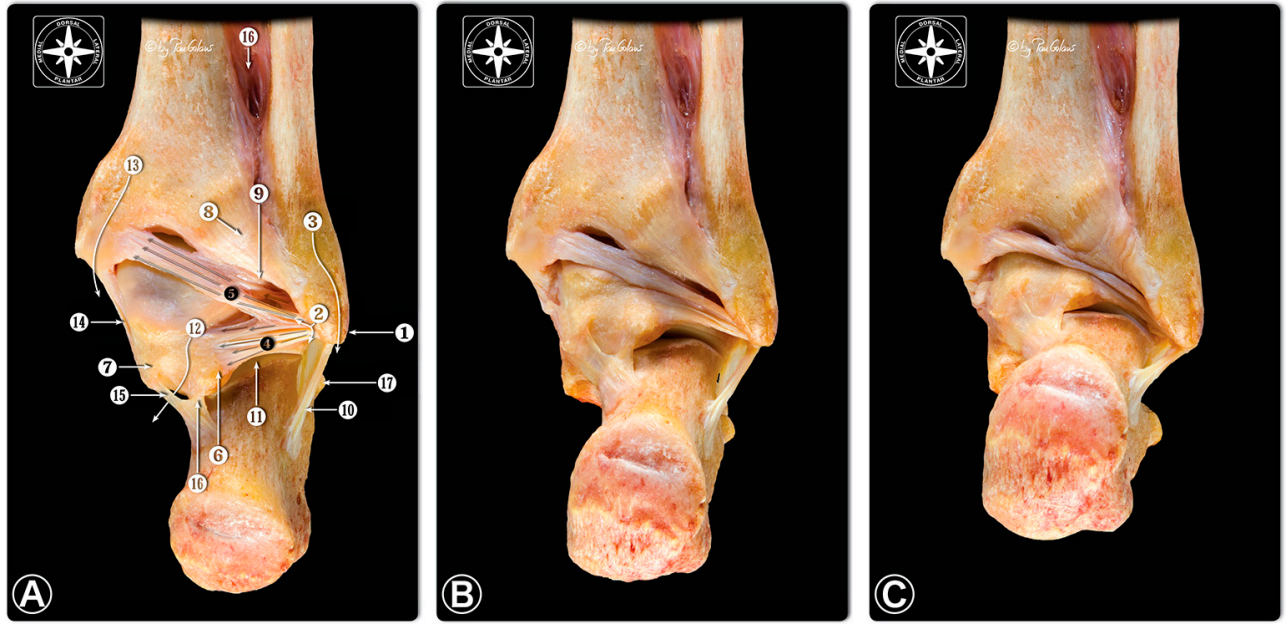

Figure 1 Posterior view of the anatomical dissection of the ankle ligaments showing the posterior intermalleolar ligament with its relation to the surrounding anatomy. The capsule was removed. (A) Dorsal flexion, (B) neutral position and (C) plantar flexion. The posterior intermalleolar ligament tenses during dorsiflexion and relaxes during plantar flexion. Trauma that causes forced dorsiflexion of the ankle can be assumed to produce injury to-or rupture of-this ligament or osteochondral avulsion. Plantar flexion would cause it to relax and become susceptible to trapping between the tibia and the talus, leading to impingement (from van Dijk, CN, Ankle Arthroscopy, 2014, Springer; reproduced with permission of van Dijk ${ }^{57}$ ) CDr. Pau Golano. 1. Lateral malleolus. 2. Malleolar fossa. 3. Peroneal groove of the fibula and peroneal tendons traject. 4. Posterior talofibular ligament. 5. Posterior intermalleolar ligament. 6. Lateral talar process. 7. Medial talar process. 8. Superficial component of the posterior tibiofibular ligament. 9. Deep component of the posterior tibiofibular ligament or transverse ligament. 10. Calcaneofibular ligament. 11. Subtalar joint. 12. Tunnel for the flexor hallucis longus tendon. 13. Tibialis posterior tendon traject. 14. Medial collateral ligament. 15. Flexor hallucis longus retinaculum. 16. Posterior talocalcaneal ligament. 17. Interosseous membrane.

which can be confirmed or excluded by means of history taking and physical examination (table 1). A patient with subtalar pathology has deep ankle pain which cannot be easily reproduced by physical examination. Locking is a sign of a loose body. Hindfoot pain, which aggravates with plantar flexion, is typical for posterior impingement. Numbness is a sign of a tarsal tunnel syndrome. Each examination begins with inspection and malalignment must be looked for specifically. The location of the pain is an important indicator. On physical examination, it is important to look for recognisable tenderness on palpation (figure 2). Not all disorders of the hindfoot can be diagnosed on palpation, but recognisable tenderness over one of the tendons guides the diagnosis in the direction of a tendon disorder.

\section{Box 1 Key articles on posterior ankle arthroscopy}

- First description of the two-portal technique with the patient in the prone position by van Dijk et al showing good results with a 2-year follow-up.

- In 2006, Pau Golanó published two articles providing detailed insight in the anatomy of the ankle with the focus on the salient facts for arthroscopists. ${ }^{5859}$

- The low complication rate per technique was outlined by the research group of Zengerink et al. ${ }^{23}$

- A recent overview on causes, diagnosis, surgical technique, outcomes and complications is provided by Smyth et al. ${ }^{18}$

- In 2015, Hayashi et a $/{ }^{60}$ provided a radiographic overview on posterior ankle impingement, including the differentials that should be taken into account.

- To assess the safety of the posterior approach of ankle arthrodesis, Kerkhoffs et $a /{ }^{61}$ performed a cadaveric study to assess iatrogenic damage after posterior ankle arthroscopic procedure.
The posterolateral talar process can be palpated on the posterolateral side of the ankle with the ankle in $15-20^{\circ}$ plantar flexion. The posterior medial talar process can be palpated on the posteromedial side of the talus. It is important to determine the range of motion (ROM) of both the ankle joint and the subtalar joint and to compare both sides. At the conclusion of the examination, a posterior impingement test is performed (figure 2) Recognisable posterior pain, confirms the diagnosis of posterior ankle impingement . Finally, the neurological and vascular status of the foot must be determined.

For posterior impingement, a lidocaine injection can be used for diagnostics, as it should result in a negative hyperplantar flexion test. The os trigonum is visible on lateral ankle radiographs, but it can be better visualised using a posterior impingement viewmade with the ankle in $25^{\circ}$ external rotation (PIM-view). ${ }^{12} 13$ Deep ankle pain is the main symptom of an OCD. Often routine ankle radiographs are negative. ${ }^{14-16}$ To determine the extent and location of an OCD and to determine if an anterior or a posterior ankle arthroscopic approach is required, a CT scancan be used. Verhagen has shown that both CT scan and MRI have a similar accuracy in detecting an OCD. ${ }^{17}$ For preoperative planning, a CT scan is preferable to determine the location and extent of the lesion and location of bony fragments. MRI is the imaging method of choice for evaluating soft tissue injury and bone bruises, but may overestimate the size of an OCD due to bone oedema. Ultrasonography is a relatively inexpensive and reliable alternative to MRI for detecting focal soft tissue damage. ${ }^{18}$ In case the diagnosis remains unclear in spite of all additional diagnostics the patient will likely not benefit from (diagnostic) arthroscopy. ${ }^{19}$ In case of suspicion of joint degeneration or OA, a standing radiograph may show joint space narrowing. ${ }^{20}$

Preoperative severity of complaints may be assessed using patient reported outcome measures (table 2). These may additionally be used to evaluate postoperative recovery. 
Table 1 Key issues of patient selection

\begin{tabular}{|c|c|c|c|}
\hline Indication & History & Physical examination & Additional diagnostics \\
\hline OCD treatment & Deep ankle pain & $\begin{array}{l}\text { The pain cannot be provoked by palpation with } \\
\text { the ankle in a neutral position }\end{array}$ & $\begin{array}{l}\text { In case an X-ray does not show an OCD, a } \\
\text { CT scan or MRI may be used. } \\
\text { CT scan for preoperative planning and } \\
\text { determination of the size of the lesion }\end{array}$ \\
\hline $\begin{array}{l}\text { Posterior ankle } \\
\text { impingement }\end{array}$ & Activity associated posterior ankle pain & Hyper plantar flexion test & $\begin{array}{l}\text { Posterior impingement view to identify an os } \\
\text { trigonum }\end{array}$ \\
\hline $\begin{array}{l}\text { Deltoid ligament/Cedell } \\
\text { fracture }\end{array}$ & $\begin{array}{l}\text { Hyperdorsiflexion or eversion trauma } \\
\text { Posteromedial ankle pain aggravated by } \\
\text { running or walking on uneven ground }\end{array}$ & $\begin{array}{l}\text { Recognisable pain by palpation of the } \\
\text { posteromedial (retromalleolar) region }\end{array}$ & $\begin{array}{l}\text { CT scan for affirmation of avulsion/fracture/ } \\
\text { calcification }\end{array}$ \\
\hline Tarsal tunnel syndrome & Posteromedial ankle pain & Sensory and motor nerve examination & Electromyography \\
\hline Loose body & Activity associated ankle pain or locking & No specific findings & $\begin{array}{l}\text { CT scan for affirmation of loose bodies and their } \\
\text { location }\end{array}$ \\
\hline Arthrodesis & $\begin{aligned} & \text { Deep ankle pain } \\
& \text { Failed conservative treatment } \\
& \text { No other appropriate surgical option } \\
& \text { (shared decision-making) }\end{aligned}$ & $\begin{array}{l}\text { ROM limitation } \\
\text { Crepitation } \\
\text { Deformation }\end{array}$ & Standing X-ray to confirm joint space narrowing \\
\hline
\end{tabular}

OCD, osteochondral defect; ROM, range of motion.

\section{Non-operative treatment}

Most ankle injuries are primarily treated non-operatively. If conservative treatment fails, surgery can be considered. Athletes require a quick return to play and may be eligible for acute surgical treatment. ${ }^{18}$

\section{Surgical techniques}

The operative approach to hindfoot pathology can be performed by means of open or arthroscopic surgery. Hindfoot pathology concerning tendons may also require a hindfoot approach. The best approach for this category of pathology is by tendoscopy. Tendoscopy is, however, not the focus of this review. For hindfoot and posterior ankle arthroscopy, a two-portal hindfoot approach is used and is routinely performed as a day care procedure. Generally, no prophylactic antibiotics are given. A $4 \mathrm{~mm} 30^{\circ}$ angle arthroscope or an $11 \mathrm{~cm}$ length $2.7 \mathrm{~mm}$ scope with high-volume sheath $(4.6 \mathrm{~mm})$ is used..$^{5}$ The procedure is performed under general or neuraxial anaesthesia. A tourniquet is placed around the upper thigh, but arthroscopic surgery can also be performed without the use of a tourniquet. ${ }^{21} \mathrm{Kim}$ et $a l^{22}$ described a technique for the treatment of concurrent anterior and posterior ankle impingement, in which the patient was placed in a prone position, with the ankle hung in a shoulder-holding traction frame and the application of non-invasive ankle distraction.

\section{Posterior ankle arthroscopy}

For posterior ankle arthroscopy, the patient is placed in the prone position, with the ankle overhanging the end of the table,

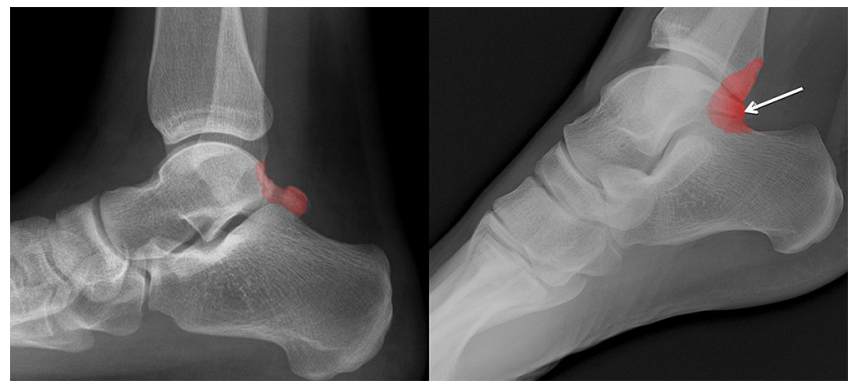

Figure 2 Pain experienced with posterior ankle impingement, intensified by maximal plantar flexion due to entrapment of soft and bony tissue. or with a triangular cushion under the distal tibia (figure 3). ${ }^{23} 24$ Using a two-portal approach, posterior ankle pathology can be visualised and subsequently treated. ${ }^{19}$ For subtalar arthrodesis and for a fibular groove deepening procedure, an additional third portal is used. ${ }^{14}$

The posterolateral portal is initially created at the level of the tip of the lateral malleolus and the arthroscope is introduced, with the initial view direction being $30^{\circ}$ to the lateral side. ${ }^{25}$ Care must be taken to avoid damage to the sural nerve. The posteromedial portal is then made at the same level (figure 4). A vertical stab incision is made and a mosquito clamp introduced. If scar tissue or adhesions are present, the mosquito clamp is exchanged for a $4.5 \mathrm{~mm}$ or $5.5 \mathrm{~mm}$ full radius shaver. Surgical debridement to improve the view is then commenced laterally-at the level of the subtalar joint, subsequently moving slowly towards the FHL. The FHL tendon is important to identify, as the neurovascular bundle lies just medial to it. For this reason, the area lateral to the FHL tendon is considered 'safe'. Passive motion of the great toe may help to identify the tendon. After removal of the thin ankle joint capsule, the joint itself can be entered, inspected and treated. ${ }^{1218192324}$

\begin{tabular}{|c|c|c|}
\hline Indication & Outcome measure & Classification \\
\hline All indications & $\begin{array}{l}\text { FAOS* } \\
\text { SF-36* } \\
\text { AOFAS } \\
\text { VAS-FA } \\
\text { FAAM }\end{array}$ & NA \\
\hline $\begin{array}{l}\text { Impingement } \\
\text { - Posterior impingement }\end{array}$ & & $\begin{array}{l}\text { Osteoarthritis scale, van Dijk et } \\
\text { al. }^{1062 *}\end{array}$ \\
\hline Osteoarthritis & $\begin{array}{l}\text { Ankle osteoarthritis } \\
\text { scale }^{963}\end{array}$ & $\begin{array}{l}\text { Osteoarthritis scale, van Dijk et } \\
\text { al. } .^{1062 *}\end{array}$ \\
\hline$O C D$ & & $\begin{array}{l}\text { CT classification, Ferkel }{ }^{64 *} \\
\text { MRI classification, Hepple }\end{array}$ \\
\hline
\end{tabular}

${ }^{*}$ Approved by the ISAKOS scientific committee.

AOFAS, American Orthopaedic Foot and Ankle Society Scor ${ }^{67}$; FAAM, Foot and Ankle Ability Measure ${ }^{68}$; FAOS, Foot and Ankle Outcome Score ${ }^{66}$; NA, not available; OCD, osteochondral defect; SF-36, Short Form (36) Health Surve ${ }^{66}$; VAS-FA, Visual Analogue Score Foot and Ankle. ${ }^{69}$ 


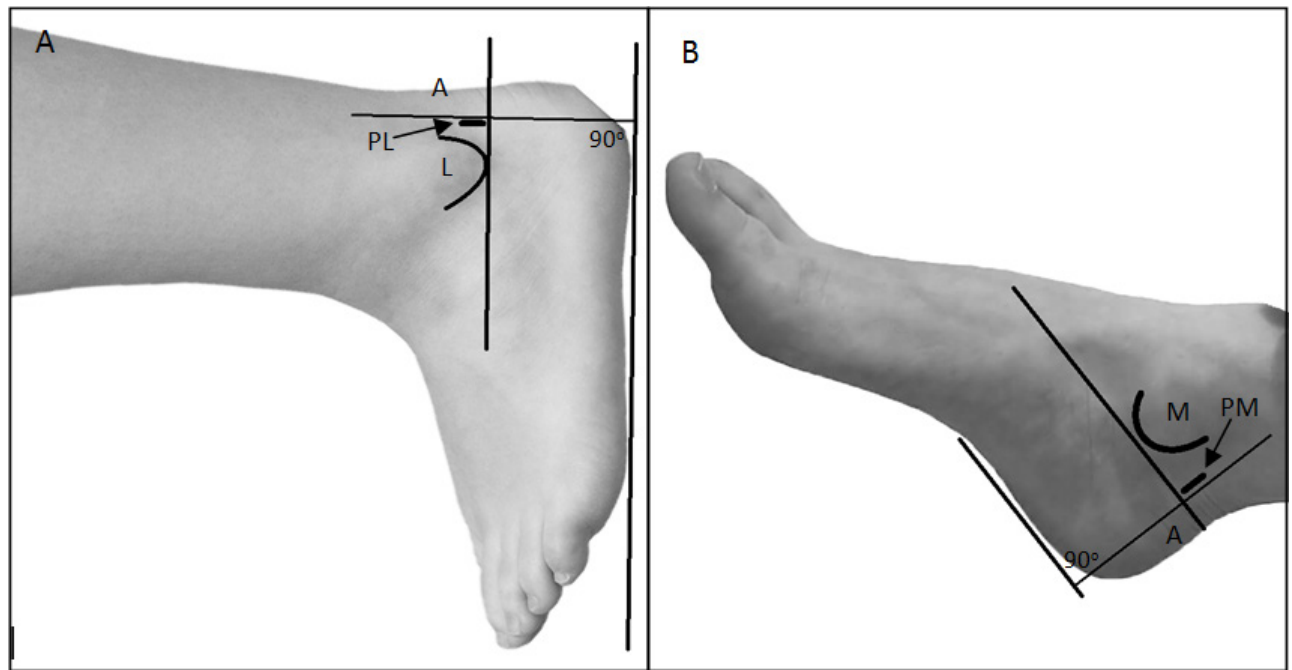

Figure 3 (A) The ankle is kept in a neutral position for making the anatomic landmarks that are needed for portal placement. To define the portal location, a straight line is drawn from the tip of the lateral malleolus to the Achilles tendon, parallel to the sole of the foot. ( $A=A c h i l l e s$ tendon, $L=l a t e r a l$ malleolus and $\mathrm{PL}=$ posterolateral portal). The posterolateral portal is made just above the line from the tip of the lateral malleolus to the Achilles tendon. (B) The posteromedial portal (PM) is located at the same level as the posterolateral portal, just in front of the medial aspect of the Achilles tendon. (M=medial malleolus). Caption is copied from the figure 7 of de Leeuw et al. ${ }^{14}$

\section{Surgical indications}

Arthroscopic surgery offers advantages such as direct visualisation of structures, improved assessment of articular cartilage, decreased postoperative morbidity, improved rehabilitation (both more rapid and also in terms of better functionality), earlier resumption of sports and improved day care treatment. ${ }^{19}$

The main pathologies that can be treated with hindfoot arthroscopy are posteriorly located OCDs, loose bodies, ossicles, post-traumatic calcifications, avulsion fragments, posterior tibial rim osteophytes, chondromatosis and chronic synovitis (table 3). ${ }^{26}$ Pathology of the subtalar joint like osteophytes or loose bodiescan also be treated by means of hindfoot arthroscopy.Extra-articular structures that can be treated with hindfoot arthroscopy are the hindfoot ankle tendons, the deep portion of the deltoid ligament and a symptomatic os trigonum . 12252728 Phisitkul et $a l^{29}$ showed that, in patients with early-stage OA, arthroscopic debridement was useful in the treatment of impingement syndromes. Additional indications for which hindfoot arthroscopy may be used is the treatment of posteriorly located intraosseous talar cysts, talar body fractures and pigmented villonodular synovitis. Finally hindfoot endoscopy can be used to perform ankle arthrodesis or a subtalar arthrodesis.

\section{Osteochondral defect}

Talar OCD's are mainly post-traumatic. Due to the post-traumatic origin concomitant ankle instability is not uncommon. ${ }^{30-32}$ Post-traumatic OCDs may remain asymptomatic or may even heal. A significant number however, progresses to deep ankle pain exacerbated during weight bearing. Symptoms includeprolonged swelling, joint stiffness, recurrent synovitis, catching and locking. Non-surgical therapy has a success rate of $45 \% .^{12} 18$ The

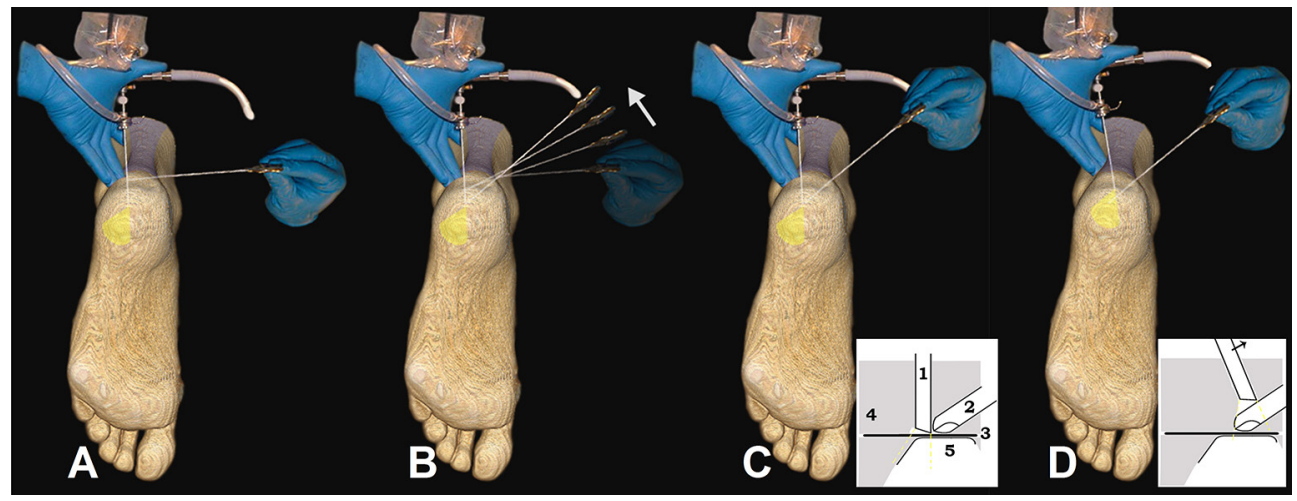

Figure 4 Technique to orient the arthroscope and instrument for posterior ankle arthroscopy with the aim of approaching the posterior aspect of the talocrural joint for excision of the os trigonum or posterior bony spurs. (A) The arthroscope is inserted in the posterolateral portal in the direction of the space between the first and second toe. The arthroscope touches the bone. The direction of view is $30^{\circ}$ to the lateral side. The shaver is introduced through the medial portal and pushed anteriorly to the Achilles tendon to touch the shaft of the arthroscope. (B) The tip of the shaver is moved down along the shaft of the arthroscope to meet the arthroscope where it touches the bone. (C) 1—arthroscope; 2 - shaver; 3-Rouviere ligament; 4-fatty tissue and 5-talus/ calcaneus. (D) The arthroscope is moved backward and tilted to the medial side to bring the tip of the shaver into view. From this position, the shaver can be used to carefully remove the Rouviere ligament and fatty tissue to create a working area with a clear view of the posterior aspect of the talus and talocrural and subtalar joints. 
Table 3 Essential and typical features of diagnostics and surgical procedures

\begin{tabular}{|c|c|c|}
\hline Indication & Diagnostic findings & Surgical treatment \\
\hline OCD treatment & $\begin{array}{l}\text { Deep ankle pain } \\
\text { Bone marrow oedema on MRI } \\
\text { Identify cysts and loose fragments }\end{array}$ & $\begin{array}{l}\text { Arthroscopy first choice (anterior, posterior or both, depending the } \\
\text { location of the lesion) }\end{array}$ \\
\hline Posterior ankle impingement & Os trigonum or prominent posterior talar process & Posterior arthroscopy \\
\hline Deltoid ligament/Cedell fracture & Calcifications and avulsion fragments on CT scan & $\begin{array}{l}\text { Removal avulsion fragments and calcifications } \\
\text { Ligament reconstruction in case of persistent medial instability }\end{array}$ \\
\hline Tarsal tunnel syndrome & $\begin{array}{l}\text { Space occupying lesions } \\
\text { Deformities }\end{array}$ & $\begin{array}{l}\text { Local corticosteroid injections } \\
\text { Orthoses for foot deformities } \\
\text { Physiotherapy } \\
\text { Release of tibial nerve (endoscopic) }\end{array}$ \\
\hline Loose body removal & $\begin{array}{l}\text { Chondral or post-traumatic origin } \\
\text { Avulsion fragments } \\
\text { Concomitant OCD }\end{array}$ & Posterior arthroscopy \\
\hline $\begin{array}{l}\text { Arthrodesis } \\
\text { Tibiotalar fusion } \\
\text { Subtalar fusion } \\
\text { Double fusion }\end{array}$ & $\begin{array}{l}\text { Tibiotalar osteoarthritis } \\
\text { Sequelae of a fracture } \\
\text { Subtalar osteoarthritis } \\
\text { - Symptomatic combined arthrosis }\end{array}$ & $\begin{array}{l}\text { - Standard portals with accessory anteromedial portal in case of } \\
\text { 'bowler-hat' shaped talus } \\
\text { Standard posterolateral and medial portal } \\
\text { - Possible use of two accessory para-Achilles tendon portals } \\
\text { - Minimal resection joint surface to avoid destabilisation }\end{array}$ \\
\hline
\end{tabular}

OCD, osteochondral defect.

treatment of choice for OCDs, in lesions less than $15 \mathrm{~mm}$ in diameter, is arthroscopic debridement associated with subchondral bone penetration (curettage, drilling or microfracture). ${ }^{12} 181933$ No firm recommendations on the treatment of lesions greater than $15 \mathrm{~mm}$ can be made at present, due to the lack of evidence currently in the literature. ${ }^{34}$

If an OCD is diagnosed, ankle CT scan may help determine the exact size and location of the lesion (table 4). A CT scan in plantar flexion may also help to determine if an anterior or a posterior approach is indicated. ${ }^{17}$ Generally, treatment of an OCD is based on one of the following three principles:

1. debridement and bone marrow stimulation, potentially in combination with loose body removal (microfracture, abrasion arthroplasty or drilling);

2. securing a lesion to the talar dome (retrograde drilling, bone grafting or fragment fixation);

3. stimulating the development of hyaline cartilage (osteochondral autografts mosaicplasty, allografts or autologous chondrocyte implantation). ${ }^{35}$

As described by van Dijk et al, ${ }^{12}$ in an update on arthroscopic techniques, he cites 'In these procedures, a $4.0 \mathrm{~mm}$ scope and a 4.5 - or $5.5 \mathrm{~mm}$ shaver are routinely used. If synovitis is present, a local synovectomy is performed with the ankle in dorsiflexion. The lesion is identified in forced plantar flexion by palpating the cartilage with a probe. A soft tissue distractor can be applied if needed. The full-radius resector is then introduced into the defect. In some cases, identifying the defect by introducing a spinal needle, probe, or curette can be useful before introducing the resector'.

To increase the chance of success, it is important to identify the full defect (including the anterior part) and to remove unstable cartilage and necrotic subchondral bone. Hyaluron injections may improve surgical results after performing microfracture and debridement. ${ }^{36}$ After the procedure a compression dressing is applied. ${ }^{12}$ Good to excellent results have been reported for arthroscopic treatment of posteriorly located OCDs in $80 \%-87 \%$ of patients. ${ }^{17} 23$

\section{Posterior ankle impingement}

Posterior ankle arthroscopy has highlighted the need for specific anatomical knowledge, modified the classic arthroscopic tools and skills and has introduced a broad spectrum of new indications in posterior ankle pathology. ${ }^{12}$

Posterior ankle impingement is not always caused by bony pathology. It frequently presents as a soft tissue impediment, with or without a bony component. ${ }^{12}$

Posterior ankle impingement syndrome consists of a group of pathologies characterised by posterior ankle pain in plantar flexion, frequently occurring in ballet dancers, downhill runners and football players. ${ }^{12} 1828$ The mechanism of injury can be overuse or trauma. Differentiation between these two groups

Table 4 Essential and typical features of imaging techniques used in the diagnostic process of an OCD 177071

\begin{tabular}{lll}
\hline Imaging tool & CT scan & MRI \\
\hline Lesion size & High accuracy of both size and location & Overestimation if size due to bone oedema \\
Concomitant damage & Additional bony fragments and osteophytes & Additional soft-tissue lesions \\
Preoperative planning & A CT scan in forced plantar flexion (sagittal reconstruction) helps to & \\
determine whether anterior or posterior approach is required & No loose body detection \\
Negatives & No cartilage visualisation & No correct estimation of the size of the bony lesion \\
Radiation exposure & lonising radiation & No ionising radiation \\
Diagnostic accuracy & Sensitivity $81 \%$ & Sensitivity $96 \%$ \\
& Specificity $99 \%$ & Specificity $96 \%$ \\
& Positive predicting value $96 \%$ & Positive predicting value $89 \%$ \\
Negative predicting value $94 \%$ & Negative predicting value $99 \%$
\end{tabular}


is important, as the prognosis for posterior impingement from overuse is better, and these patients are more satisfied after arthroscopic treatment. ${ }^{19} 37$ The hyperplantar flexion test is considered positive for posterior impingement if it causes recognisable posterior ankle pain. Additionally, the physician can perform a diagnostic injection with lidocaine. Surgical resection is indicated in case of failure of conservative treatment. ${ }^{18} 28$

The main procedures are resection of an os trigonum, reduction of a prominent posterior talar process, and removal of a soft tissue impediment. ${ }^{12}{ }^{38-40}$ In addition to the standard instruments for treatment of osteophytes and ossicles, a $4 \mathrm{~mm}$ chisel and small periosteal elevator can be used. ${ }^{12}$ In order to be able to remove the posterior process or os trigonum, the surgeon will need to release the posterior talocalcaneal ligament and flexor retinaculum and partially detach the posterior talofibular ligament. This creates enough working area to lift the os trigonum from the subtalar joint using a small-sized bone elevator. Subsequently, a grasper can be used to remove the fragment. Postoperatively, a sterile compression dressing is applied around the ankle. $^{12}$

In the series of Spennachio et $a l^{26}$ arthroscopic treatment of posterior impingement provided excellent results and clinical improvement in all cases. In the series of Lopez et $a l,{ }^{41}$ the Visual Analogue Scale for pain showed a decrease in reported pain from 7.5 preoperatively to $0.8,1$ month postoperatively. Overall, posterior ankle arthroscopy is considered safe and effective in the treatment of posterior ankle impingement in the elite football player, with an expected return to training of 5 weeks. ${ }^{42}$

\section{Deep portion of the deltoid ligament and Cedell fracture}

Two conditions often seen together are rupture of the deep portion of the deltoid ligament (posterior talotibial ligament (PTTL)) and a Cedell fracture. Both originate from a hyperdorsiflexion-or eversion trauma leading to an avulsion of the PTTL at its insertion (medial talar tubercle). Calcifications are not an uncommon result after this trauma. The most distinctive symptoms include posteromedial ankle pain, worsening by activities such as running and walking on uneven ground. Avulsion fragments, post-traumatic calcifications or ossicles in the deep portion of the deltoid ligament can be treated by removal of these bony structures. ${ }^{19}$ The avulsion fragment lies medial and anterior to the FHL; thus, care has to be taken to protect the neurovascular bundle. It is important to stay close to the bone and use blunt dissection with a small sized periosteal elevator. If persistent chronic medial instability is present, ligament reconstruction can be carried out using a free graft of the plantaris tendon, with tendon allograft being an alternative. Given the continuing evolution of the anatomical understanding of this ligament, current treatment protocols for deltoid injuries require further standardisation, with an emphasis on proper diagnosis. ${ }^{43}$

\section{Tarsal tunnel syndrome}

Tarsal tunnel syndrome is an entrapment neuropathy of the tibial nerve. The cause is often ideopathic but factors such as trauma, space-occupying lesions and deformities of the foot have been shown to be related to its development. ${ }^{44}$ Clinically, patients may report symptoms that are difficult to localise, and physical examination findings vary greatly leading to underdiagnosis and misdiagnosis. A thorough history taking should ascertain any causative factors. Additionally, electromyography may support the diagnosis; however, a normal electromyogram does not exclude a tarsal tunnel syndrome. It has been shown that sensory nerve examination has a higher sensitivity compared with motor nerve examination. ${ }^{45} 46$ Conservative treatment consists of local corticosteroid injections, orthoses for foot deformities and physiotherapy. If conservative treatment fails, endoscopic decompression is a good option. After identification of the FHL tendon, the fascia covering the tibial nerve is opened with a haemostat. The fascia is opened over its full length thereby exposing the tibial nerve. Adhesions are identified and the nerve is freed along its entire length.

\section{Loose bodies}

Loose bodies may be chondral or osteochondral in origin and can be post-traumatic or result from an OCD. Multiple loose bodies may develop in case of chondromatosis or synovial osteochondromatosis. Loose bodies can cause pain, swelling, decreased ROM and locking. They do not necessarily float freely within the joint capsule but may also be fixed to synovium, thereby being semi-loose bodies or ossicles. On a standard ankle radiograph, loose bodies can easily be missed. A CT scan is the additional investigation of choice. Localisation is important in order to facilitate and determine the best surgical approach for extraction.

\section{Arthrodesis \\ Tibiotalar arthrodesis}

For arthroscopic tibiotalar arthrodesis, the standard two-portal technique used in hindfoot arthroscopy is used. For debridement, routine instruments are used: a $5.5 \mathrm{~mm}$ Bone-cutter shaver blade, a curved curette and a $5.0 \mathrm{~mm}$ osteotome. An accessory anteromedial portal may provide outcome in case of a 'bowler-hat' shaped talus to ensure complete debridement of the anterior part of the talus and distal tibia.

After full cartilage removal, including the joint gutters, the subchondral bone is removed until a bleeding bone surface is attained. The contour of the talus (and distal tibia) has to be kept intact. Two $6.5 \mathrm{~mm}$ cancellous compression screws are inserted through a midline incision and through the Achilles tendon. The excellent intra-articular operating area provides the ability to optimise hindfoot alignment and the easy orientation of the two screws intraoperatively. For this reason, the posterior approach is preferred over the anterior procedure. Fluoroscopy may be used as guidance for screw insertion.

After surgery, patients are kept in a non-weight bearing cast for 6 weeks. Depending on clinical and radiographic assessment, a walker-or weight-bearing cast-is applied for another 4-6 weeks. After radiographic fusion, the patient is allowed to wear normal shoes and resume activities, as tolerated. In summary, posterior arthroscopic fusion has proven to be an effective and safe option at mid-term follow-up in the treatment for progressed post-traumatic ankle osteoarthritis. ${ }^{47}$

\section{Subtalar arthrodesis}

The main indications for subtalar arthroscopy are sequelae of a fracture, a sprain or subtalar osteoarthritis. The first arthroscopic subtalar arthrodesis was described by Parisien $e{ }^{a} l^{48}$ which was a lateral and posterolateral approach. Later popularised by van Dijk et $a l^{5}$ an exclusively posterior approach was described. Preoperatively, an anteroposterior (AP) and lateral weight-bearing ankle X-ray should be performed and a CT scan can also be useful in preoperative planning. ${ }^{49}$ To perform a subtalar arthrodesis using posterior ankle arthroscopy, the patient is positioned prone with a tourniquet around the thigh. The foot is left free, hanging over the end of the table with the ability to place the ankle in a $90^{\circ}$ angle. Routine posterolateral and posteromedial portals 
are created as previously described. After identification of the subtalar joint, all cartilage is removed using curved curettes and a shaver system. ${ }^{50}$ A third sinus tarsi portal fascilitates debridement of the anterior compartment of the subtalar joint. Fixation is performed, with two large-diameter $(>6 \mathrm{~mm})$ cannulated screws which are introduced through a separate incision at the level of the posterior calcaneus. ${ }^{5}$

Postoperatively, the ankle is immobilised using a removable non-weight bearing cast for 4-6weeks, followed by a weight bearing cast for another 4-6weeks. Arthroscopy has improved the results when compared with open arthrodesis-significantly reducing non-union rates and with fewer neurovascular complications. ${ }^{49}$

\section{Double fusion}

Through a posterior arthroscopic approach, double fusion (combined tibiotalar and subtalar arthrodesis) can be performed. Double fusion may be indicated in case of symptomatic combined arthrosis of the ankle joint and subtalar joint. Bernage et al ${ }^{51}$ described the double fusion using two additional para-Achilles tendon portals. Minimal resection of the joint surfaces of both the subtalar and tibiotalar joint are described to avoid destabilisation of the joint. A tibial hindfoot nail is used for fixation, which is introduced through an incision on the sole of the foot. First, a transplantar K-wire is introduced which allows subsequent introduction of reamers and the nail. Final osteochondral resection is performed with the K-wire still in place. Postoperative treatment is similar to that of the subtalar and ankle arthrodesis.

\section{Contraindications to surgery}

Absolute contraindications for any form of ankle arthroscopy include local (soft-tissue) infection, severe degenerative joint disease and poor vascularity of the leg. Moderate degenerative changes with diminished ROM, severe oedema, joint space narrowing and diabetic vascular disease account for relative contraindications. ${ }^{141824}$

\section{Complications}

Overall hindfoot arthroscopy is regarded to be a safe procedure. Nevertheless, adequate preoperative planning and the use of a careful, precise technique is important. The most common complications include neurological problems, sinus tract formation, vascular damage, synovitis and wound infection. ${ }^{23}$ The proximity of the medial neurovascular bundle to the posteromedial portal is the major concern for posterior ankle arthroscopy. Not only the use of the posteromedial portal is a risk factor for postoperative complications, but also the posterolateral portal which is close to the sural nerve. Inadequate portal positioning may cause damage to this nerve (box 2 and 3). ${ }^{18}$ Knowledge and understanding of the ankle joint anatomy help reducing these complications. ${ }^{19}$ Donnenwerth et $a l^{52}$ reported complications in $3.8 \%$ of cases after hindfoot arthroscopy and Blazquez Martin et $a l^{53}$ reported complications in $12.06 \%$ of cases. Zengerink reported $2.3 \%$ of complications for hindfoot arthroscopy alone. $^{23}$

\section{GEOGRAPHICAL DIFFERENCES}

There have been reports of additional portals used in the technique of posterior arthroscopy. Two additional posterolateral portals have been described for the removal of os trigonum. Ferkel described removal of os trigonum by standard subtalar portals. ${ }^{54}$ These approaches have not met with great acceptance. The posterior approach cannot be regarded as state of art for
Box 2 Tips and tricks for successful posterior arthroscopy

- For correct orientation and reproducibility, always start with the arthroscope in the posterolateral portal.

- Instruments introduced through the posteromedial portal are inserted perpendicular to the arthroscopic shaft. The shaft is subsequently used as a guide to direct instruments anteriorly. The direction of the arthroscopic view ( $30^{\circ}$ angulation) is routinely towards the lateral side for optimal and consistent orientation throughout the procedure.

- It may be helpful to enlarge the entry point through the crural fascia using a punch or scissors.

- Identify the flexor hallucis longus (FHL) tendon. The FHL serves as a landmark. Avoid instrumentation medial to the FHL.

In OCD treatment, it is advised to regularly switch portals.

ankle arthrodesis. The majority of current literature reports on performing an ankle arthrodesis through two anterior portals. For endoscopic double fusion, the posterior approach can be considered as state of art. For subtalar fusion in Europe, the two-portal hindfoot approach is mainly used. In the USA, some perform the two-portal hindfoot approach, but others report using the classic subtalar portals with the patient in lateral decubitus position. ${ }^{55}$

In South America, arthroscopic surgeons use the two classic posterior portals as previously described. Most ankle surgeons in this region do not use dedicated instruments specifically designed for the ankle joint. The same problem occur with drills. In Argentina, for example, 95\% of drills used in surgeries, are not specifically designed for arthroscopy.

A common issue in the Middle East is the high incidence of athletes with vitamin $\mathrm{D}$ deficiency. ${ }^{56}$ In combination with triggering sports, this potentially can lead to early initiation of bony posterior impingement syndromes.

\section{FUTURE DIRECTIONS}

Currently, the two-portal hindfoot arthroscopy technique is safe and accepted for most indications. In the future, more indications will undoubtedly arise, given the ongoing studies in combination with the use of hindfoot arthroscopy and new higher quality evidence emerging. This will strengthen current recommendations and further help orthopaedic specialists in evidencebased practice. $^{26}$

Expansion of endoscopic soft tissue techniques in the hindfoot will likely be a major avenue of study. Currently, arthroscopy

\section{Box 3 Pitfalls in posterior ankle arthroscopy}

- Identify the flexor hallucis longus tendon and work lateral to this tendon, as the neurovascular bundle is situated just medial to it.

- When microfracturing, an osteochondral defect, loose bony particles can be created with the microfracture which may act as loose bodies if not properly removed.

- After peroneal groove deepening for recurrent peroneal tendon dislocation, the ankle is manipulated to check whether sufficient bone has been removed. Removing too much bone may result in a fracture of the lateral rim. To avoid damage to the tendon, the lateral edge of the groove should be smoothed. 
is being performed for assessment and treatment of disorders of the peroneal tendon, posterior tibial tendon and Achilles tendon. For the Achilles tendon in particular, these techniques have been shown to be beneficial and future expansion in this direction can be anticipated.

Acknowledgements With special thanks to the heirs of Pao Golano for permission to use figure 1. We additionally thank Dr Peter Dzendrowski for help in preparing and finalising this manuscript.

Competing interests None declared.

Provenance and peer review Commissioned; externally peer reviewed.

(c) International Society of Arthroscopy, Knee Surgery and Orthopaedic Sports Medicine (unless otherwise stated in the text of the article) 2017. All rights reserved. No commercial use is permitted unless otherwise expressly granted.

\section{REFERENCES}

1 Kerkhoffs G, Leeuw PAJd, d'Hooghe P. Posterior ankle impingement. In: The ankle in football. Sports and traumatology. France: Springer, 2014.

2 Brown TD, Johnston RC, Saltzman CL, et al. Posttraumatic osteoarthritis: a first estimate of incidence, prevalence, and burden of disease. J Orthop Trauma 2006;20:739-44.

3 Takagi K. The arthroscope. Jpn J Orthop Assn 1939;14.

4 Ferkel RD, Fischer SP. Progress in ankle arthroscopy. Clin Orthop Relat Res 1989;240:210-20.

5 van Dijk CN, Scholten PE, Krips R. A 2-portal endoscopic approach for diagnosis and treatment of posterior ankle pathology. Arthroscopy 2000;16:871-6.

6 van Dijk CN, Kort N, Scholten PE. Tendoscopy of the posterior tibial tendon. Arthroscopy 1997;13:692-8.

7 Niek van Dijk C, Scholten PE, Kort NP. Tendoscopy (tendon sheath endoscopy) for overuse tendon injuries. Oper Tech Sports Med 1997;5:170-8.

8 van Bergen CJ, de Leeuw PA, van Dijk CN. Treatment of osteochondral defects of the talus. Rev Chir Orthop Reparatrice Appar Mot 2008;94(Suppl 8):398-408.

9 Watanabe M. Sefloc-arthroscope (Watanabe no. 24 arthroscope). Monograph. Tokyo: Teishin Hospital, 1972.

10 Burman MS, Peltier LF, Burman MS. Arthroscopy or the direct visualization of Joints: an experimental cadaver study. Clin Orthop Relat Res 2001:390:5-9.

11 Coughlin MJ, Mann RA, Saltzman CL. Surgery of the Foot and Ankle 8th rev. ed. Amsterdam: Mosby Elsevier, 2006

12 van Dijk CN, van Bergen CJ. Advancements in ankle arthroscopy. J Am Acad Orthop Surg 2008;16:635-46.

13 Wiegerinck JI, Vroemen JC, van Dongen TH, et al. The posterior impingement view: an alternative conventional projection to detect bony posterior ankle impingement. Arthroscopy 2014;30:1311-6

14 de Leeuw PA, van Sterkenburg MN, van Dijk CN. Arthroscopy and endoscopy of the ankle and hindfoot. Sports Med Arthrosc 2009;17:175-84.

15 Niek van Dijk C. Anterior and posterior ankle impingement. Foot Ankle Clin 2006;11:663-83.

16 Siparsky PN, Kocher MS. Current concepts in pediatric and adolescent arthroscopy. Arthroscopy 2009:25:1453-69.

17 Verhagen RA, Maas M, Dijkgraaf MG, et al. Prospective study on diagnostic strategies in osteochondral lesions of the talus. is MRI superior to helical CT? J Bone Joint Surg $\operatorname{Br} 2005 ; 87: 41-6$

18 Smyth NA, Zwiers R, Wiegerinck Jl, et al. Posterior hindfoot arthroscopy: a review. Am J Sports Med 2014;42:225-34.

19 M.L R, v.S.M.N. deL, van Dalen PAJ, et al. Ankle arthroscopy: indications, techniques and complications. SA Orthopaedic Journal 2009:51-58.

20 Kraus VB, Kilfoil TM, Hash TW, et al. Atlas of radiographic features of osteoarthritis of the ankle and hindfoot. Osteoarthritis Cartilage 2015;23:2059-85.

21 Zaidi R, Hasan K, Sharma A, et al. Ankle arthroscopy: a study of tourniquet versus no tourniquet. Foot Ankle Int 2014:35:478-82.

22 Kim HK, Jeon JY, Dong Q, et al. Ankle arthroscopy in a hanging position combined with hindfoot endoscopy for the treatment of concurrent anterior and posterior impingement syndrome of the ankle. J Foot Ankle Surg 2013;52:704-9.

23 Zengerink M, van Dijk CN. Complications in ankle arthroscopy. Knee Surg Sports Traumatol Arthrosc 2012:20:1420-31.

24 van Dijk CN, Scholte D. Arthroscopy of the ankle joint. Arthroscopy 1997;13:90-6.

25 van Dijk CN. Hindfoot endoscopy. Foot Ankle Clin 2006;11:391-414.

26 Spennacchio P, Cucchi D, Randelli PS, et al. Evidence-based indications for hindfoot endoscopy. Knee Surg Sports Traumatol Arthrosc 2016;24:1386-95.

27 Ogut T, Ayhan E, Irgit K, et al. Endoscopic treatment of posterior ankle pain. Knee Surg Sports Traumatol Arthrosc 2011:19:1355-61.

28 van Dijk CN. Hindfoot endoscopy for posterior ankle pain. Instr Course Lect 2006:55:545-54.

29 Phisitkul P, Tennant JN, Amendola A. Is there any value to arthroscopic debridement of ankle osteoarthritis and impingement? Foot Ankle Clin 2013;18:449-58.
30 Lee J, Hamilton G, Ford L. Associated intra-articular ankle pathologies in patients with chronic lateral ankle instability: arthroscopic findings at the time of lateral ankle reconstruction. Foot Ankle Spec 2011;4:284-9.

31 Bonnel F, Toullec E, Mabit C, et al. Chronic ankle instability: biomechanics and pathomechanics of ligaments injury and associated lesions. Orthop Traumatol Surg Res 2010;96:424-32.

32 Odak S, Ahluwalia R, Shivarathre DG, et al. Arthroscopic evaluation of impingement and osteochondral lesions in chronic lateral ankle instability. Foot Ankle Int 2015;36:1045-9.

33 Donnenwerth MP, Roukis TS. Outcome of arthroscopic debridement and microfracture as the primary treatment for osteochondral lesions of the talar dome. Arthroscopy 2012;28:1902-7.

34 Glazebrook MA, Ganapathy V, Bridge MA, et al. Evidence-based indications for ankle arthroscopy. Arthroscopy 2009;25:1478-90.

35 Zengerink M, Szerb I, Hangody L, et al. Current concepts: treatment of osteochondral ankle defects. Foot Ankle Clin 2006;11:331-59.

36 Doral MN, Bilge O, Batmaz G, et al. Treatment of osteochondral lesions of the talus with microfracture technique and postoperative hyaluronan injection. Knee Surg Sports Traumatol Arthrosc 2012:20:1398-403.

37 van Dijk CN, de Leeuw PA, Scholten PE. Hindfoot endoscopy for posterior ankle impingement. Surgical technique. J Bone Joint Surg Am 2009;91(Suppl 2):287-98.

38 Brennan SA, Rahim F, Dowling J, et al. Arthroscopic debridement for soft tissue ankle impingement. Ir J Med Sci 2012;181:253-6.

39 Galla M, Lobenhoffer P. Technique and results of arthroscopic treatment of posterior ankle impingement. Foot Ankle Surg 2011;17:79-84.

40 Jerosch J, Fadel M. Endoscopic resection of a symptomatic os trigonum. Knee Surg Sports Traumatol Arthrosc 2006;14:1188-93.

41 López Valerio V, Seijas R, Alvarez P, et al. Endoscopic repair of posterior ankle impingement syndrome due to os trigonum in soccer players. Foot Ankle Int 2015:36:70-4.

42 Calder JD, Sexton SA, Pearce CJ. Return to training and playing after posterior ankle arthroscopy for posterior impingement in elite professional soccer. Am I Sports Med 2010;38:120-4.

43 Savage-Elliott I, Murawski CD, Smyth NA, et al. The deltoid ligament: an in-depth review of anatomy, function, and treatment strategies. Knee Surg Sports Traumatol Arthrosc 2013;21:1316-27.

44 Lau JT, Daniels TR. Tarsal tunnel syndrome: a review of the literature. Foot Ankle Int 1999;20:201-9.

45 Galardi G, Amadio S, Maderna L, et al. Electrophysiologic studies in tarsal tunnel syndrome. diagnostic reliability of motor distal latency, mixed nerve and sensory nerve conduction studies. Am J Phys Med Rehabil 1994;73:193-8.

46 Oh SJ, Sarala PK, Kuba T, et al. Tarsal tunnel syndrome: electrophysiological study. Ann Neurol 1979;5:327-30

47 de Leeuw PA, Hendrickx RP, van Dijk CN, et al. Midterm results of posterior arthroscopic ankle fusion. Knee Surg Sports Traumatol Arthrosc 2016;24:1326-31.

48 Parisien JS. Arthroscopy of the posterior subtalar joint: a preliminary report. Foot Ankle 1986;6:219-24.

49 Roussignol X. Arthroscopic tibiotalar and subtalar joint arthrodesis. Orthop Traumatol Surg Res 2016;102(Suppl 1):S195-203.

50 van Dijk CN, Vuurberg G, Amendola A, et al. Anterior ankle arthroscopy: state of the art. Journal of ISAKOS: Joint Disorders \& Orthopaedic Sports Medicine 2016;1:105-15.

51 Bevernage BD, Deleu PA, Maldague P, et al. Technique and early experience with posterior arthroscopic tibiotalocalcaneal arthrodesis. Orthop Traumatol Surg Res 2010:96:469-75

52 Donnenwerth MP, Roukis TS. The incidence of complications after posterior hindfoot endoscopy. Arthroscopy 2013;29:2049-54.

53 Blázquez Martín T, Iglesias Durán E, San Miguel Campos M. Complications after ankle and hindfoot arthroscopy. Rev Esp Cir Ortop Traumatol 2016:60:387-93.

54 Ferkel RD, Scranton PE. Arthroscopy of the ankle and foot. J Bone Joint Surg Am 1993:75:1233-42.

55 Tasto JP. Arthroscopy of the subtalar joint and arthroscopic subtalar arthrodesis. Instr Course Lect 2006:55:555-64.

56 Green RJ, Samy G, Miqdady MS, et al. Vitamin D deficiency and insufficiency in Africa and the Middle East, despite year-round sunny days. S Afr Med J 2015;105:603-5.

57 van Dijk CN. Ankle arthroscopy: techniques developed by the Amsterdam Foot and Ankle School. Heidelberg, New York, Dodrecht, London: Springer-Verlag Berlin Heidelberg, 2014:408

58 Golanó P, Vega J, Pérez-Carro L, et al. Ankle anatomy for the arthroscopist. Part II: role of the ankle ligaments in soft tissue impingement. Foot Ankle Clin 2006;11:275-96.

59 Golanó P, Vega J, Pérez-Carro L, et al. Ankle anatomy for the arthroscopist. Part I: the portals. Foot Ankle Clin 2006;11:253-73.

60 Hayashi D, Roemer FW, D'Hooghe P, et al. Posterior ankle impingement in athletes: pathogenesis, imaging features and differential diagnoses. Eur J Radiol 2015;84:2231-41

61 Hendrickx RP, de Leeuw PA, Golano P, et al. Safety and efficiency of posterior arthroscopic ankle arthrodesis. Knee Surg Sports Traumatol Arthrosc 2015;23:2420-6. 
62 Tol JL, Verheyen CP, van Dijk CN. Arthroscopic treatment of anterior impingement in the ankle. J Bone Joint Surg Br 2001;83:9-13.

63 Domsic RT, Saltzman CL. Ankle osteoarthritis scale. Foot Ankle Int 1998;19:466-71.

64 Ferkel RD SN, Del Pizzo W, et al. Arthroscopic treatment of osteochondral lesions of the talus: technique and results. Orthop Tran 1990;14:3.

65 Hepple S, Winson IG, Glew D. Osteochondral lesions of the talus: a revised classification. Foot Ankle Int 1999;20:789-93.

66 Roos EM, Brandsson S, Karlsson J. Validation of the foot and ankle outcome score for ankle ligament reconstruction. Foot Ankle Int 2001;22:788-94.

67 Ibrahim T, Beiri A, Azzabi M, et al. Reliability and validity of the subjective component of the American Orthopaedic Foot and Ankle Society clinical rating scales. J Foot Ankle Surg 2007;46:65-74.
68 Weel H, Zwiers R, Azim D, et al. Validity and reliability of a Dutch version of the foot and ankle ability measure. Knee Surg Sports Traumatol Arthrosc 2016;24:1348-54.

69 Richter M, Zech S, Geerling J, et al. A new foot and ankle outcome score: questionnaire based, subjective, Visual-Analogue-Scale, validated and computerized. Foot and Ankle Surgery 2006;12:191-9.

70 O'Loughlin PF, Heyworth BE, Kennedy JG. Current concepts in the diagnosis and treatment of osteochondral lesions of the ankle. Am I Sports Med 2010;38:392-404.

71 Kok AC, Terra MP, Muller S, et al. Feasibility of ultrasound imaging of osteochondral defects in the ankle: a clinical pilot study. Ultrasound Med Biol 2014;40:2530-6. 


\section{Posterior ankle arthroscopy: current state of the art}

C Niek Van Dijk, Gwendolyn Vuurberg, Jorge Batista and Pieter d'Hooghe

J ISAKOS 2017 2: 269-277 originally published online August 7, 2017 doi: 10.1136/jisakos-2016-000082

Updated information and services can be found at:

http://jisakos.bmj.com/content/2/5/269

These include:

References This article cites 65 articles, 2 of which you can access for free at: http://jisakos.bmj.com/content/2/5/269\#BIBL

Email alerting Receive free email alerts when new articles cite this article. Sign up in the service box at the top right corner of the online article.

\section{Notes}

To request permissions go to:

http://group.bmj.com/group/rights-licensing/permissions

To order reprints go to:

http://journals.bmj.com/cgi/reprintform

To subscribe to BMJ go to:

http://group.bmj.com/subscribe/ 